\title{
The Revised Edition of Korean Calendar for Allergenic Pollens
}

\author{
Jae-Won Oh, ${ }_{1}{ }^{*}$ Ha-Baik Lee, ${ }_{1}^{1}$ Im-Joo Kang, ${ }_{1}^{2}$ Seong-Won Kim, ${ }_{1}^{3}$ Kang-Seo Park, ${ }_{1}^{4}$ yyung-Hee Kook, ${ }_{1}^{5}$ Bong-Seong Kim, ${ }_{1}^{6}$ \\ Hey-Sung Baek, Joo-Hwa Kim, Ja-Kyung Kim, ${ }^{7}$ Dong-Jin Lee, ${ }_{1}^{8}$ Kyu-Rang Kim, ${ }_{1}^{9}$ Young-Jin Choi ${ }^{9}$
}

\author{
${ }^{1}$ Department of Pediatrics, College of Medicine, Hanyang University, Seoul, Korea \\ ${ }^{2}$ Department of Pediatrics, Daegu Fatima Hospital, Daegu, Korea \\ ${ }^{3}$ Department of Pediatrics, Busan St. Maria Hospital, Busan, Korea \\ ${ }^{4}$ Department of Pediatrics, Presbyterian Medical Center, Jeonju, Korea \\ ${ }^{5}$ Department of Pediatrics, Kwangju Veteran's Hospital, Kwangju, Korea \\ ${ }^{6}$ Department of Pediatrics, Kangneung Asan Hospital, Kangneung, Korea \\ 'Department of Pediatrics, School of Medicine, Kangwon National University, Chuncheon, Korea \\ ${ }^{8}$ Department of Pediatrics, Ulsan Dongkang Hospital, Ulsan, Korea \\ ${ }^{9}$ Applied Meteorology Research Laboratory, National Institute of Meteorological Research, Seoul, Korea
}

This is an Open Access article distributed under the terms of the Creative Commons Attribution Non-Commercial License (http://creativecommons.org/licenses/by-nc/3.0/) which permits unrestricted non-commercial use, distribution, and reproduction in any medium, provided the original work is properly cited.

The old calendar of pollens did not reflect current pollen distribution and concentrations that can be influenced by changes of weather and environment of each region in South Korea. A new pollen calendar of allergenic pollens was made based on the data on pollen concentrations obtained in eight regions nationwide between 1997 and 2009. The distribution of pollen was assessed every day at 9 stations (Two Seoul sites, Guri, Busan, Daegu, Daejeon, Kwangju, Kangneung, and Jeju) for 12 years and at 3 stations (Jeonju, Ulsan, and Chuncheon) for 3 years among 12 pollen collection stations. Pollens were collected by using Burkard 7-day sampler (Burkard Manufacturing Co Ltd, UK). Pollens which were stained with Calberla's fuchsin staining solution were identified and counted. Pine became the highest pollen in May, and the pollen concentrations of oak and birch also became high. Ragweed appeared in the middle of August and showed the highest pollen concentration in the middles of September. Japanese hop showed a high concentration between the middle of August and the end of September, and mugwort appeared in the middles of August and its concentration increased up until early September. In Kangneung, birch appeared earlier, pine showed a higher pollen concentration than in the other areas. In Daegu, Oriental thuja and alder produced a large concentration of pollens. Pine produced a large concentration of pollens between the middle of April and the end of May. Weeds showed higher concentrations in September and mugwort appeared earlier than ragweed. In Busan the time of flowering is relatively early, and alder and Oriental thuja appeared earliest among all areas. In Kwangju, Oriental thuja and hazelnut appeared in early February. Japanese cedar showed the highest pollen concentration in March in Jeju. In conclusion, update information on pollen calendar in South Korea should be provided for allergic patients through the website to manage and prevent the pollinosis.

Key Words: Allergens; pollen

\section{INTRODUCTION}

Allergic diseases related to pollen grains are called pollinoses and include allergic rhinitis, allergic conjunctivitis, asthma, and atopic dermatitis. Recently, numerous studies of allergic plants have been conducted in the United States and Europe, and the resulting information about allergic plants has been provided to allergy patients and the general public. ${ }^{1-3}$

Bostöck reported that pollen grains may cause diseases in humans. ${ }^{4}$ In the United States and Europe, epidemiological studies of airborne pollens have been continuously performed since the 1960s, ${ }^{5,6}$ and close relationships between pollens and allergic or pulmonary diseases have been reported since 1980. Information about clinical skin test reactions to various pollen grains has recently been provided to allergic patients and the general public through a website. In Korea, allergic pollen grains were studied in the early $1980 \mathrm{~s} .{ }^{7}$ Recently, the frequency of pollinosis, including allergic rhinitis, has increased in children, and

Correspondence to: Jae-Won Oh, MD, PhD, Department of Pediatrics, Hanyang University Guri Hospital, 249-1 Kyomun-dong, Guri 471-701, Korea. Tel: +82-31-560-2254; Fax: +82-31-552-9493; E-mail: jaewonoh@hanyang.ac.kr Received: June 27, 2011; Accepted: July 19, 2011

- There are no financial or other issues that might lead to conflict of interest. 
many studies have investigated the relationships between the concentrations of allergic pollens and the clinical manifestations of allergic diseases. ${ }^{8}$ Thus, there is a necessity for pollen forecasting or a pollen calendar for Korea in order to prevent or reduce the prevalence of pollinosis. ${ }^{9-11}$

Pollen grains are produced by various plants, but not all pollen grains cause allergic diseases. Plants can be classified as anemophilous or entomophilous according to their pollination process. Entomophilous flowers produce heavy pollen grains that are transported by insects, so these pollens are produced in small amounts and rarely cause allergic diseases. In particular, entomophilous pollens have clinical implications in cases involving gardeners or horticulturists. In contrast, because light anemophilons pollen grains are transmitted by the wind, they are produced in large amounts. These grains are associated with allergic diseases because they contain special apparatuses, such as air sacs, and can travel great distances in the air. The size of pollen grains is closely related to the development of allergic diseases, and most of the pollen grains which can induce allergic diseases have sizes of 20 to $60 \mu \mathrm{m} .{ }^{12}$ Because the diameter of bronchioles is 3 to $5 \mu \mathrm{m}$, pollen grains with diameters smaller than $5 \mu \mathrm{m}$ can reach the bronchioles. Asthma induced by pollens may be explained by the mechanism in which aeroallergens are inhaled, mix with sputum, and adhere to the respiratory mucosa. Another plausible mechanism is that some grains dissolve in airway mucus before being swallowed and entering the gastrointestinal tract. ${ }^{1-18}$

\section{Collection and identification of pollen grains}

The distribution of airborne pollen grains was assessed daily at eight locations nationwide between July 1, 1997 and June 30, 2009. A Burkard 7-day sampler (Burkard Manufacturing Co Ltd, Hertfordshire, UK) was installed at a height of 1.5 meters above sea level. The pollen collection areas were (1) Hanyang University Seoul Hospital, (2) Seoul Meteorological Station in the Seoul metropolitan area, (3) Hanyang University Guri Hospital in the north-central region of South Korea, (4) Kangneung Asan Hospital and (5) Kangwon National University Chuncheon Hospital in the north-east, (6) Daejeon Meteorological Station in the central, (7) Kwangju Veterans Hospital and (8) Jeonju Jesus Hospital in the south-west, (9) Daegu Fatima Hospital in the south-east, (10) Busan St. Maria Hospital and (11) Ulsan Dongkang University in the far south-east, and (12) Jeju University Hospital on Jeju Island, the most distant of the southern islands (Fig. 1). Airborne pollens were collected every day from all samplers at all collection sites. The samples were sent every week to Hanyang University Guri Hospital, which was responsible for determining pollen concentrations. After each glycerin adhesive plastic was stained with Calberla's fuchsin staining solution (glycerin $10 \mathrm{~mL}, 95 \%$ alcohol $20 \mathrm{~mL}$, distilled water 30 $\mathrm{mL}$, and basic fuchsin $0.2 \mathrm{~mL}$ ), the number of pollen grains per $\mathrm{m}^{3}$ was calculated at a magnification of $\times 400 .{ }^{19}$ Pollens were

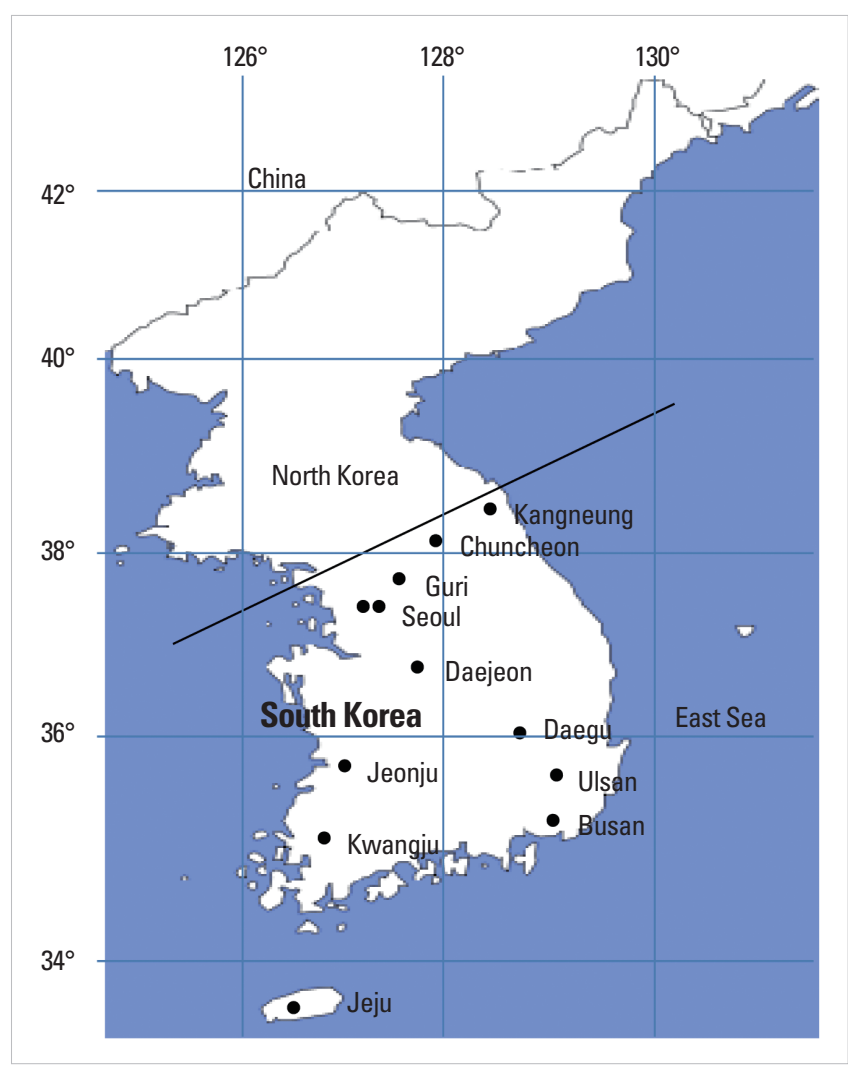

Fig. 1. The twelve pollen collection stations in South Korea used in this study.

morphologically identified and classified by their size, color, pore shape, and surface pattern, with reference to the distribution of nationwide allergy-related plants such as trees, grasses, and weeds. ${ }^{20}$ Weather conditions on each collection day were recorded throughout the collection period and their associations with pollen distribution were assessed.

\section{Classification of pollens that cause allergic disease in Korea Trees}

Gymnosperms

Cypresses: The pollen size ranges from 20 to $30 \mu \mathrm{m}$. This pollen appears from the middle of February and is well known to induce allergic rhinitis. Juniper, cypress, and cedar belong to the Cypresses.

Pinus: The pollen ranges in size from 45 to $65 \mu \mathrm{m}$. This pollen has two sacs, and it rarely causes allergic diseases. Pines and spruces belong to Pinus (Fig. 2A).

\section{Angiosperms}

Most allergenic trees belong to this group.

Betulaceae: This pollen appears in late February (early spring) and has a strong potential to induce allergic diseases. The pollen size ranges in size from 20 to $30 \mu \mathrm{m}$. This pollen has three pores and a thin exine. Alder (Fig. 2B), hazelnut (Fig. 2C), and birch (Fig. 2D) belong to this family. 


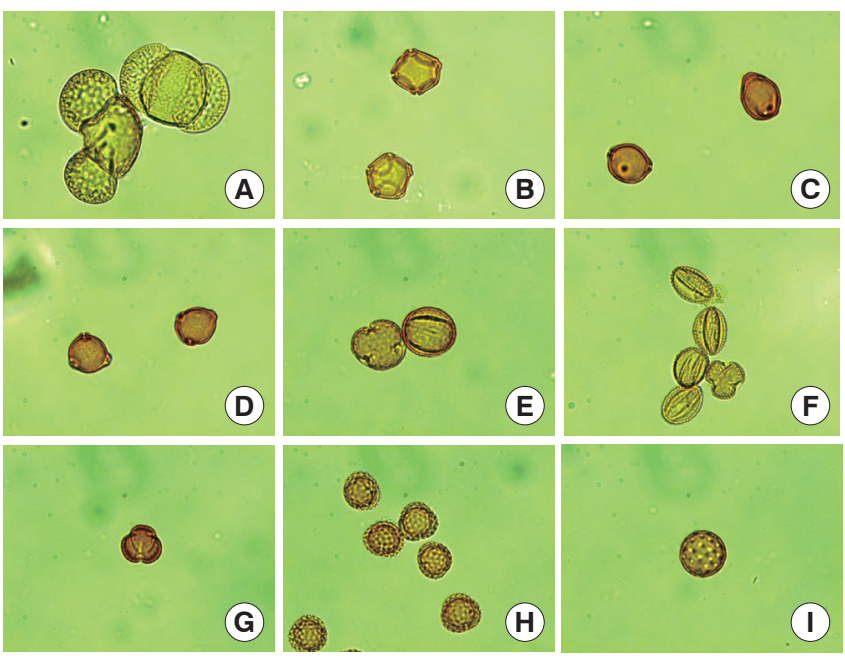

Fig. 2. Common allergic pollens that cause pollinosis in Korea. (A) Pine, (B) alder, (C),hazel, (D) birch, (E) oak, (F) willow, (G) mugwort, (H) ragweed, and (I) pigweed.

Fagaceae: This is an insect-borne pollen. This pollen appears in late March and is a representative of those allergens that induce pollinosis. It has a diameter of approximately $40 \mu \mathrm{m}$ and has an irregular exine and three characteristic furrows. Beech and oak (Fig. 2E) belong to this family.

Salicaceae: Most of the Salicaceae pollens are insect-borne, although poplar is airborne. This pollen has a strong allergenicity. It has a diameter of 20 to $34 \mu \mathrm{m}$ and has a thick intine. It appears between May and June. It has many pistils and stamens, which do not usually induce allergic diseases, although they sometimes induce contact hypersensitivity reactions. Willow (Fig. 2F) and poplar belong to this family.

Ulmaceae: This pollen induces pollinosis between May and June. It has a diameter of 30 to $40 \mu \mathrm{m}$ and has five furrows and a thick, wave-like exine.

\section{Grasses}

Grasses related to allergic diseases belong to the order Graminales. Their pollen has a diameter of 20 to $25 \mu \mathrm{m}$ and has one pore or furrow and a relatively thick intine. These pollens are airborne between the end of April and November, and have a strong allergenicity, partly because these plants are cultivated in densely-populated areas, leading to a high prevalence of pollinosis. Tens of different species are found in Korea. Although individual pollens are difficult to discriminate by light microscopy, this has no clinical implications because they cause similar allergic reactions. Korean lawn grass, timothy grass, Bermuda grass, and orchard grass are frequently found in Korea.

\section{Weeds}

Weeds are not usually cultivated and are distributed on the roadside or in creeks near the homes of many people. These pollens become airborne in late summer and are the main cause of pollinosis in the autumn.

Asteraceae: These are most commonly found in Korea during the autumn. Sagebrushes (Artemisia) and ragweeds (Ambrosia) are representative pollinosis-causing weeds.

Tribe Asteraceae: This pollen has a diameter of 20 to $30 \mu \mathrm{m}$ and has three furrows and a relatively thick exine. This is the main plant that causes pollinosis in the autumn (Fig. 2G).

Tribe Ambrosiae: This is a common cause of pollinosis in the autumn. It was imported from the United States in 1970, and became an important allergic pollen in the early 1980s. It is currently reported as a representative pollinosis-causing pollen nationwide. Ambrosia trifida (giant ragweed) and Ambrosia integrifolia, which has a stalk of 1-2.5 m, as well as Ambrosia artemisiifolia (short ragweed), which has a stalk of approximately $1 \mathrm{~m}$, are representative of this species. This pollen has a diameter of 15 to $20 \mu \mathrm{m}$ and has a multiple-thorned, ball-shaped, thick exine (Fig. 2H).

Amaranthaceae and Chenopodiaceae: After mugwort and ragweed, these are the most frequently detected pollens. They are important causes of autumn pollinosis. They have a golf ball-like appearance, which allows for easy identification, and have a diameter of 20 to $30 \mu \mathrm{m}$. It is difficult to discriminate between these two families using light microscopy, so they are designated as Chenopod-Amaranth in airborne pollen surveys (Fig. 2I).

Cannabaceae: This long-lived plant family includes voluble, diclinous, and annual plants and blossoms between August and September. It grows nationwide in fields, empty lots, and near creeks. It is found ubiquitously in embankments and apartment walls in cities and their suburbs. It grows wild in the Seoul metropolitan area where it is an important cause of autumn pollinosis. Japanese hop belongs to this family.

\section{Characteristics of pollen distribution in Korea}

Pollens are spores derived from stamens and can be divided into trees, grasses, and weeds. In Korea, allergenic pollens appear at temperatures $\geq 10^{\circ} \mathrm{C}$ between February and November. The peak seasons are spring and fall; thereafter concentrations of these pollens decrease abruptly. Tree pollens are mainly observed between March and May, grass pollens between May and September, and weed pollens between August and October. Trees include pine, oak, alder, and birch, of which pine accounts for $70 \%$ of all tree pollens. Grass pollens are difficult to discriminate from other pollens using light microscopy; detailed classification of these species can be accomplished using electron microscopy. Japanese hop, mugwort and ragweed belong to this family.

\section{Pollen concentrations and weather conditions}

Pollen concentrations are closely related to general weather conditions, such as temperature and rainfall. Temperature and rainfall are particularly important determinants of pollen 


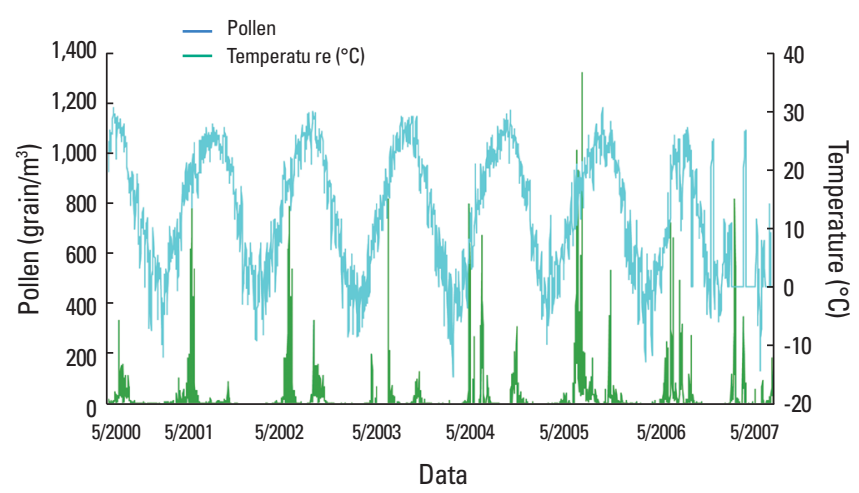

Fig. 3. Correlation between allergic pollen concentrations and air temperature. Pollens were collected at air temperatures $\geq 10^{\circ} \mathrm{C}$.

concentration. Pollens are heavily concentrated at $10-30^{\circ} \mathrm{C}$, which is the most suitable temperature for plant growth (Fig. 3 ). High concentrations of pollen occur on days without rainfall. More pollen grains are airborne when the atmospheric temperature rises immediately after rainfall.

\section{Climate changes and increased pollen concentrations}

Since the 1900s, remarkable climate changes have occurred due to rapid industrialization. Atmospheric temperature has increased due to the greenhouse effect secondary to the increased atmospheric $\mathrm{CO}_{2}$ concentration. Weather conditions, including $\mathrm{CO}_{2}$ concentration, rainfall, atmospheric temperature, humidity, wind speed, and wind direction may alter the concentrations of plant pollens and other allergens, which can subsequently influence the occurrence of asthma or allergic rhinitis. Many studies have demonstrated that $\mathrm{CO}_{2}$ concentration and increased atmospheric temperature increase pollen concentration. Ziska et al. ${ }^{21,22}$ reported that the atmosphere contains high levels of $\mathrm{CO}_{2}$ concentration due to rapid industrialization. They also predicted that pollen levels would rise due to increased $\mathrm{CO}_{2}$ concentration. Previous studies have demonstrated a significant relationship between pollen level and elevated atmospheric temperatures, and that pollen concentrations are higher in cities that have both a high atmospheric temperature and a high $\mathrm{CO}_{2}$ concentration than rural areas. ${ }^{23,24}$

\section{Climate changes and pollen characteristics}

A characteristic of climate change is that flowers blossom earlier and fall later, subsequently extending the duration of pollen production. For this reason, the annual amount of pollen has increased. It is well known that the distribution of plants, as well as the allergenicity of their pollen, have continuously changed. When subjects are sensitized to airborne pollens and are exposed to increased air pollution, allergic disease activity increases and clinical symptoms are aggravated. Such changes represent a serious global public health concern. To minimize the occurrence of clinical manifestations in allergic patients, a pollen calendar for Korea was developed between

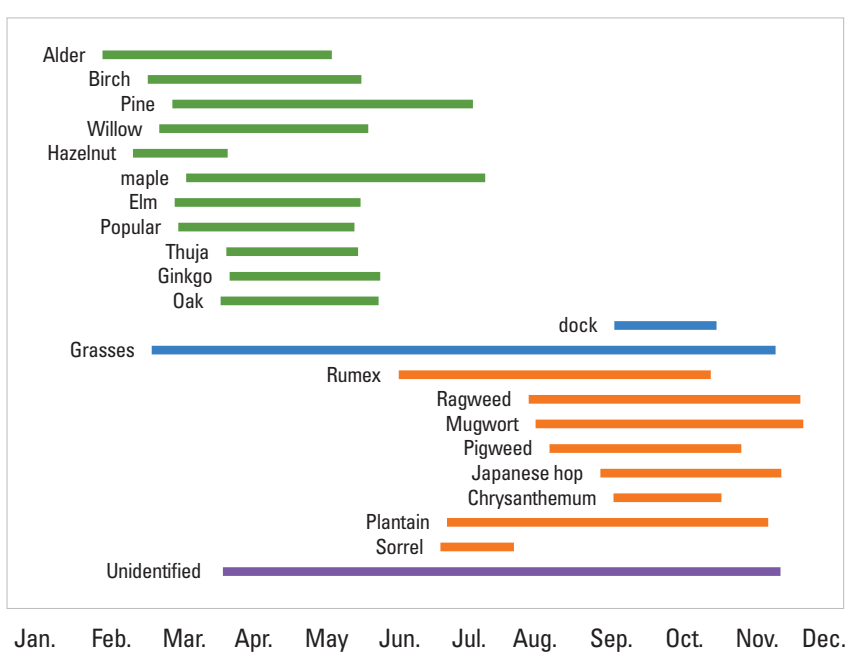

Fig. 4. A calendar of allergic pollen used nationwide since 2004 which uses pollen data collected from 1997-2002.

1997 and 2002 (Fig. 4). However, because this calendar was based on the mean concentration of pollen nationwide, it did not reflect the regional characteristics of pollens and may be inaccurate due to recent changes in the climate. Therefore, it was necessary to develop a new calendar that included the geographic and monthly distribution of pollens and included data obtained after 2004. ${ }^{25}$ The old calendars were also modified by deleting data that did not match the dates of pollen distribution as reported in previous research.

\section{Pollen calendar}

A new pollen calendar was developed based on the pollen concentration data obtained in the eight locations listed above between 1997 and 2009. Briefly, pine was the most common source of tree pollens. Overall, tree pollens were detected at higher concentrations than grass or weed pollens. Pine, alder, oak, and birch produced higher pollen concentrations between April and May. Japanese cedar and common sorrel produced higher concentrations of pollens on Jeju, which is isolated from the mainland of the Korean Peninsula.

In terms of regional variation, alder, birch, cedars, and oriental thuja began to produce pollens in February, after which their concentrations increased. In Seoul and Guri, pine pollen concentration was very high in May, when the concentrations of oak and birch pollen were also high. Common ragweed appeared at $5 / \mathrm{m}^{3} /$ day in the middle of July; its concentration was highest in the middle of September. Japanese hop pollen levels were highest between the middle of August and the end of September. Mugwort pollen appeared in the middle of August and its concentration increased up until early September (Fig. 5). Birch pollen appeared earlier (early February) in Kangneung than in the other areas; pine pollen also appeared at higher concentrations in Kangneung than in other areas (Fig. 6). However there is not enough data to make a pollen calendar 


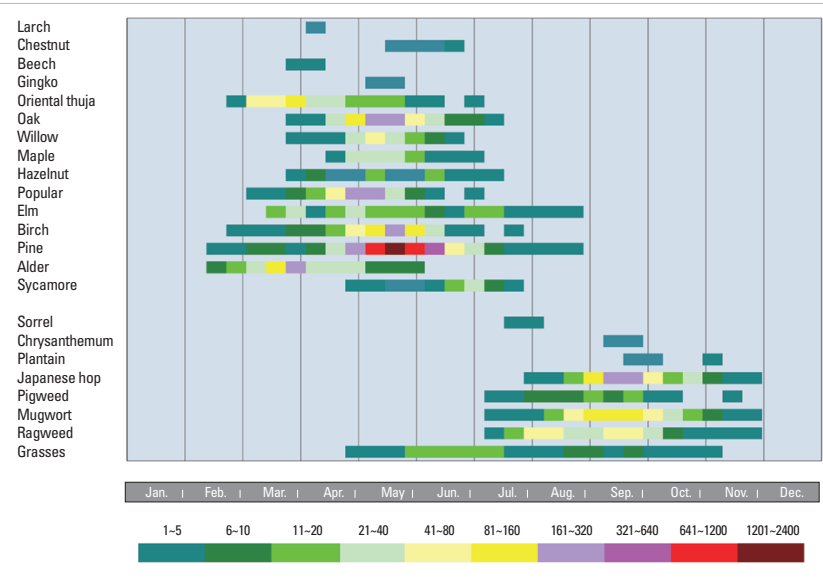

Fig. 5. An allergic pollen calendar for Seoul and Guri.

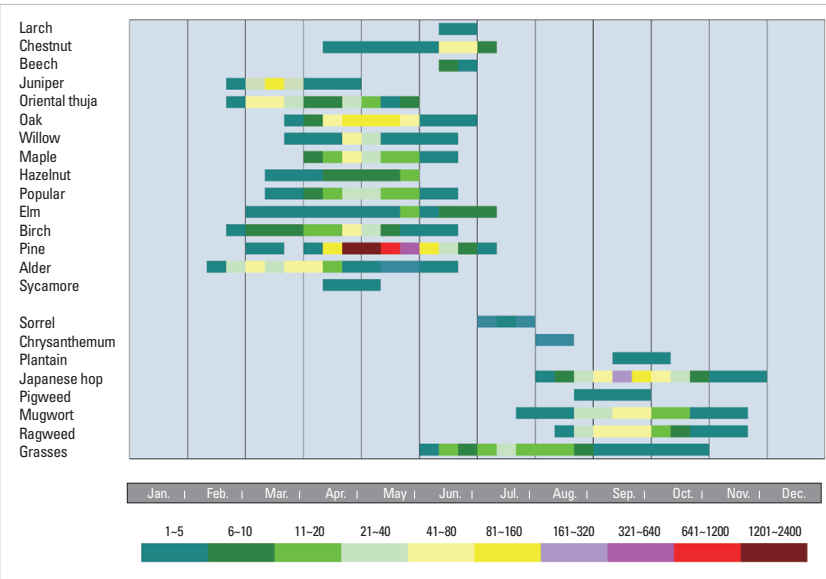

Fig. 7. An allergic pollen calendar for Daegu.

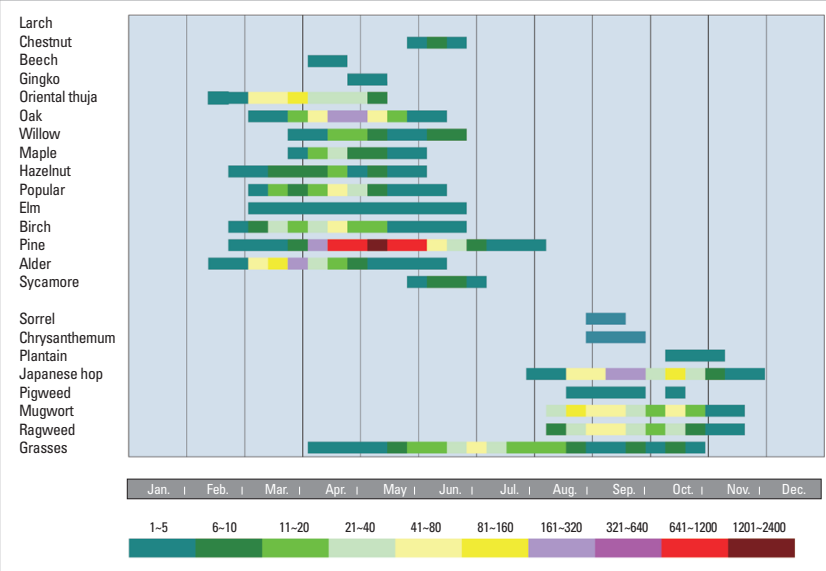

Fig. 9. An allergic pollen calendar for Daejeon.

in Chuncheon because pollens were collected since 2010. In the Daegu area, oriental thuja, alder, and juniper produced a large amount of pollens in March. Pine produced a large amount of pollen between the middle of April and the end of May. Weed

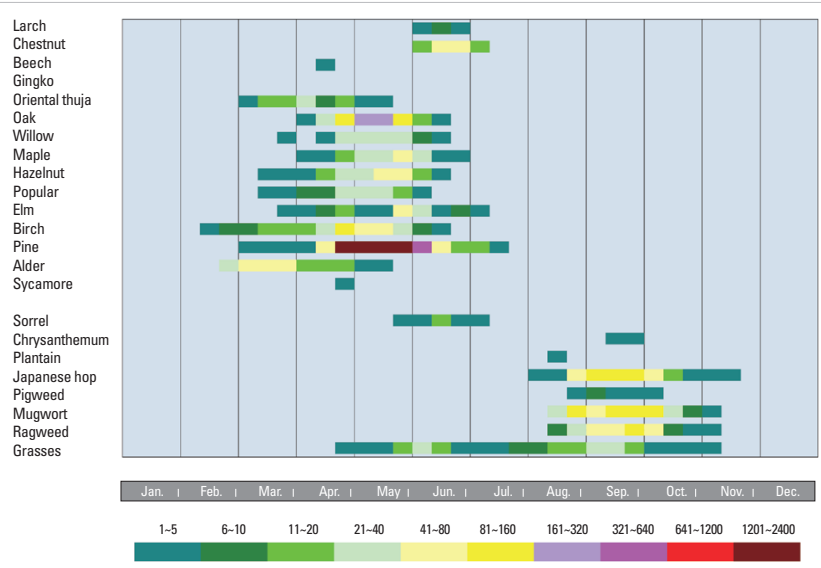

Fig. 6. An allergic pollen calendar for Kangneung.

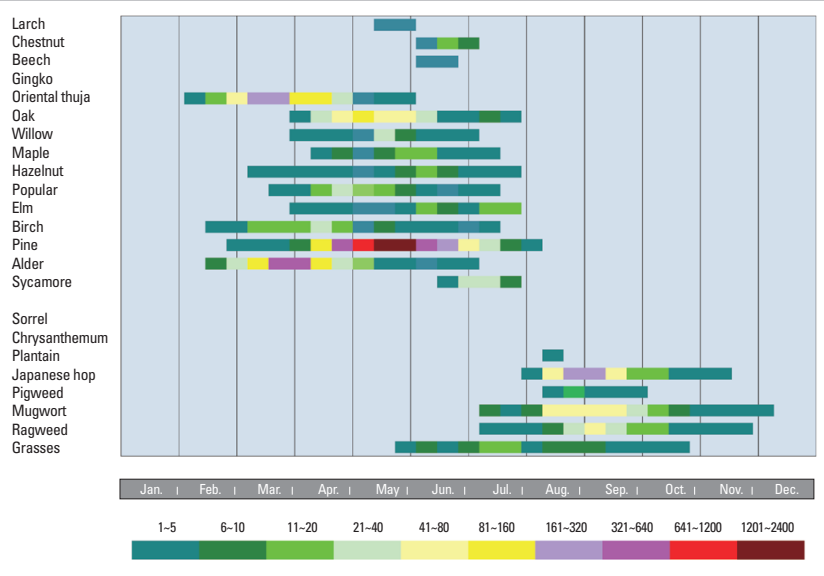

Fig. 8. An allergic pollen calendar for Busan.

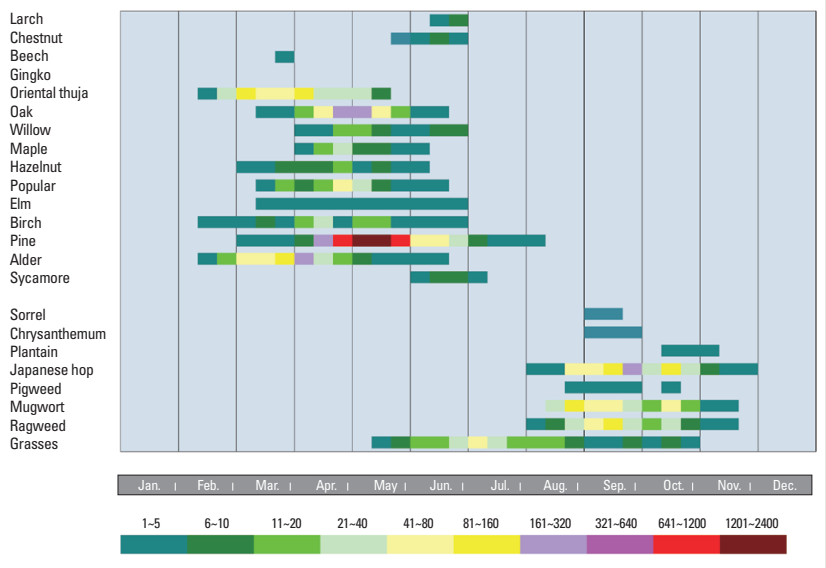

Fig. 10. An allergic pollen calendar for Kwangju.

pollen concentrations were higher in September as in the other areas, and mugwort pollen was produced earlier than common ragweed pollen (Fig. 7). In Busan, flowering occurred relatively early, and alder and oriental thuja pollens appeared here before 


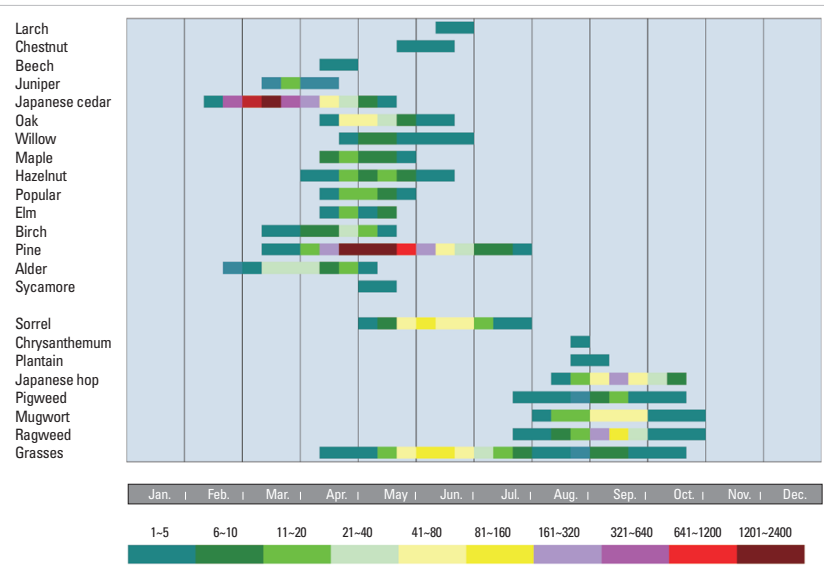

Fig. 11. An allergic pollen calendar for Jeju.

they did in other areas (early February) (Fig. 8). However there is not enough data to make a pollen calendar in Ulsan because pollens were collected since 2010. In Daejeon, birch and alder produced pollens earlier than in the other areas. Pine pollen was present at high levels between the beginning of April and the end of May (Fig. 9). In the Kwangju, oriental thuja and hazelnut pollens appeared in early February (Fig. 10). But there is not enough data to make a calendar in Jeonju because pollens were collected since 2009. In the Jeju area, Japanese cedar pollen appeared at higher concentrations than in other areas in March and peaked between the middle of February and March. Additionally, common sorrel pollen appeared at high levels between May and June. These results reflect the characteristics of Jeju (Fig. 11).

In conclusion, the pollen calendar in South Korea made between 1997 and 2002 does not reflect current pollen distribution and concentrations, because these have been altered by changes in the weather and environment. Therefore, updated information on pollen distribution and concentration in each region should be provided to the general public and allergy patients through a website in order to manage and prevent pollinosis.

\section{ACKNOWLEDGMENTS}

This study was supported by the grant from the National Institute of Meteorological Research, 2007-2009 and the fund from the pollen study committee of the Korean Academy of Pediatric Allergy and Respiratory Diseases (KAPARD).

\section{REFERENCES}

1. Lewis WH, Vinay P, Zenger VE. Airborne and allergenic pollen of North America. Baltimore: Johns Hopkins University Press; 1983.

2. Min YG. The pathophysiology, diagnosis and treatment of allergic rhinitis. Allergy Asthma Immunol Res 2010;2:65-76.
3. Jung JW, Choi JC, Shin JW, Kim JY, Park IW, Choi BW. Clinical characteristics according to sensitized allergens in adult Korean patients with bronchial asthma. Allergy Asthma Immunol Res 2010;2:102-7.

4. Taylor G, Walker J, Backley CH. 1820-1900: A detailed description of the astonishing achievement of Backley in describing the causes of hay fever. Clin Allergy 1973;3:103-8.

5. Lewis WH, Imber WE. Allergy epidemiology in the St. Louis, Missouri, area: II grasses. Ann Allergy 1975;35:42-50.

6. Anderson JH. Allergenic airborne pollen and spores in Anchorage, Alaska. Ann Allergy 1985;54:390-9.

7. Kang SY, Min KU. Aerobiological and allergic study of pollen in Seoul. Allergy 1984;4:1-20.

8. Oh YC, Kim HA, Kang IJ, Cheong JT, Kim SW, Kook MH, Kim BS, Lee HB, Oh JW. Evaluation of the relationship between pollen count and the outbreaks of allergic diseases. Pediatr Allergy Respir Dis 2009;19:354-64.

9. Oh JW, Lee HB, Lee HR, Pyun BY, Ahn YM, Kim KE, Lee SY, Lee SI. Aerobiological study of pollen and mold in Seoul, Korea. Allergol Int 1998;47:263-70.

10. Oh JW, Lee HR, Kim JS, Lee KI, Kang YJ, Kim SW, Kook MH, Kang HY, Kim JS, Lee MH, Lee HB, Kim KE, Pyun BY, Lee SI, Han MJ. Aerobiological study of pollen and mold in the 10 states of Korea. Pediatr Allergy Respir Dis 2000;10:22-33.

11. Oh JW, Kang IJ, Kim SW, Kook MH, Kim BS, Shin KS, Hahn YS, Lee HB, Shon MH, Cheong JT, Lee HR, Kim KE. The correlation between increased sensitization rate to weeds in children and the annual increase in weed pollen in Korea. Pediatr Allergy Respir Dis 2006;16:114-21.

12. Brown HM, Irving KR. The size and weight of common allergenic pollens. An investigation of their number per microgram and seze distribution. Acta Allergol 1973;28:132-8.

13. Potter PC, Cadman A. Pollen allergy in South Africa. Clin Exp Allergy 1996;26:1347-54.

14. Esch RE, Bush RK. Aerobiology of outdoor allergens. In: Adkinson NF Jr, Middleton E, Yunginger JW, Busse WW, Bochner BS, Holgate ST, Simons FE, editors. Middleton's allergy principles and practice. 6th ed. St. Louis: Mosby; 2003. 529-55.

15. Solomon WR, Weber RW, Dolen WK. Common allergenic pollen and fungi. In: Bierman CW, Pearlman DS, Shapiro GG, Busse WW, editors. Allergy, asthma, and immunology from infancy to adulthood. 3rd ed. Philadelphia: WB Saunders; 1996. 93-114.

16. Solomon WR, Burge HA, Muilenberg ML. Allergen carriage by atmospheric aerosol. I. Ragweed pollen determinants in smaller micronic fractions. J Allergy Clin Immunol 1983;72:443-7.

17. Agarwal MK, Swanson MC, Reed CE, Yunginger JW. Immunochemical quantitation of airborne short ragweed, Alternaria, antigen E, and Alt-I allergens: a two-year prospective study. J Allergy Clin Immunol 1983;72:40-5.

18. Marsh D. Allergens and the genetics of allergy. In: Sela M, editor. The antigens. Vol. 3. New York: Academic Press; 1975. 271-6.

19. Løwenstein H. Quantitative immunoelectrophoretic methods as a tool for the analysis and isolation of allergens. Prog Allergy 1978; 25:1-62.

20. Smith EG. Sampling and identifying allergenic pollens and molds: an illustrated identification manual for air samplers. San Antonio: Blewstone Press; 1990.

21. Ziska $\mathrm{LH}$, Caulfield FA. Rising $\mathrm{CO}_{2}$ and pollen production of common ragweed (Ambrosia artemisiifolia), a known allergy-inducing species: implications for public health. Australian J Plant Physiol 
2000;27:893-8.

22. Ziska LH, Gebhard DE, Frenz DA, Faulkner S, Singer BD, Straka JG. Cities as harbingers of climate change: common ragweed, urbanization, and public health. J Allergy Clin Immunol 2003;111:290-5.

23. Wayne P, Foster S, Connolly J, Bazzaz F, Epstein P. Production of allergenic pollen by ragweed (Ambrosia artemisiifolia $\mathrm{L}$.) is increased in $\mathrm{CO}_{2}$-enriched atmospheres. Ann Allergy Asthma Immunol 2002; 88:279-82.
24. Singer BD, Ziska LH, Frenz DA, Gebhard DE, Straka JG. Increasing Amb a 1 content in common ragweed (Ambrosia artemisiifolia) pollen as a function of rising atmospheric $\mathrm{CO}_{2}$ concentration. Funct Plant Biol 2005;32:667-70.

25. Park KJ, Kim HA, Kim KR, Oh JW, Lee SY, Choi YJ. Characteristics of regional distribution of pollen concentration in Korean Peninsula. Korean J Agric Forest Meterol 2008;10:167-76. 